\title{
AN ANALYTICAL STUDY OF PATTERN OF INFORMAL REGIONS
}

\section{Ahdy Adel}

Engineer in General Organization for Physical Planning (GOPP) Ministry of Housing

(Recieved October 27, 2007 Accepted December 24, 2007)

This current research purpose is to shedding light on pattern and kinds of informal region, defining their characteristics, problems, how they are constructed in addition to the factors affecting existence of such areas. The study also discusses how these areas are violating agricultural lands, establishing small industrial zones near their inhabited places and small enterprises located there. The study attempts to consider impact of these activities on constructional, social, and economic environment, as well as the hygienic

Aspects of individuals.The research is identifying types of informal region and different varied definitions of these areas, monitoring the most significant problems they face in their environment. The research exposes the phenomenon of urbanization and the effects resulted in existence of informal region, characteristics of inhabitants there from the social and economic perspective, besides exploring reasons for living in such areas and random development of these areas.

The research is also focusing on effects of (professional - small enterprises) activities located within these blocks and their impacts on environmental, constructional, social, and economic aspects, stating solution and improvement recommendation. The research is also exploring the following:

- An analytical study of informal region, types, characteristics, problem and definition of random housing, in addition to considering its impact on constructional, environmental, and hygienic aspects.

- Reasons for establishment of such groupings.

- Monitoring the constructional, social, and economic problems and their influence on those individuals.

- Monitoring the environmental problems resulted from existence of such blockings and their impact on health of inhabitants.

- Stating the appropriate solutions as well as recommendations and strategies of dealing with these areas. 


\section{دراسـة تحليلية لانماط المنـاطق العثوائيـة . مهندس / عهنى عادل}

مهندس تخطيط عمرانى بالهيئة العامة للتخطيط العمرانى بوزارة الاسكان . المستخلص

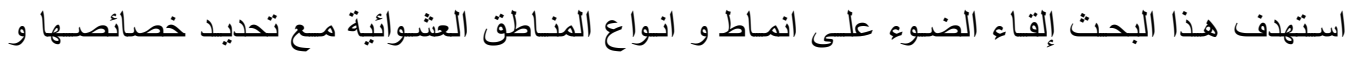

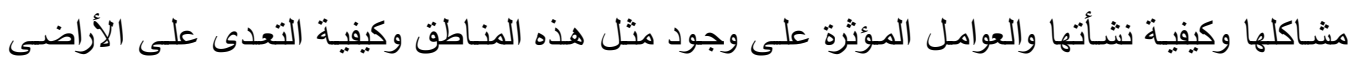

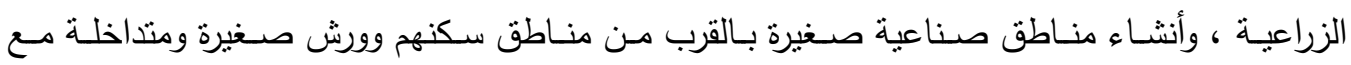

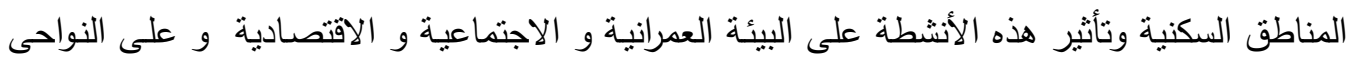

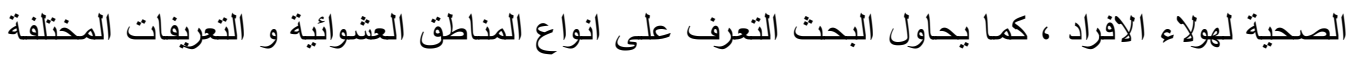
لهذة المناطق ورصد اهم المشكلات البيئية الناتجة عنها ، كما يتعرض البحث لظاهرة التحضر والآثار التى ترتبت عن وجود مثل المناطق العشوائية و خصائص السكان من النواحى الاجتماعية و الاقتصادية و اسباب السكن داخل هذة التجمعات ـ و النمو العشوائى لهذة المناطق و ازياد حركة نموها.

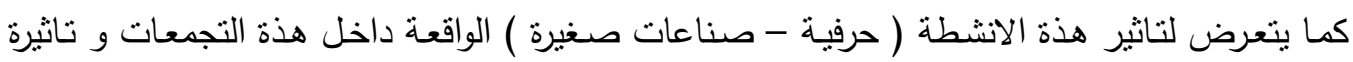

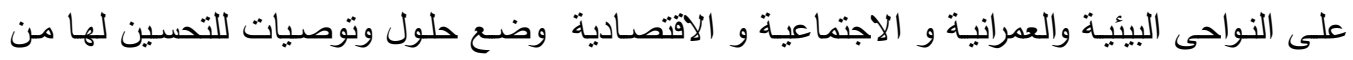

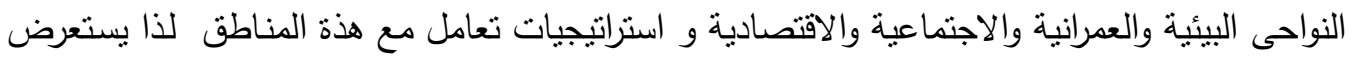
البحث :

- - دراسـة تحليلية للمناطق العشوائية وأنواعها وخصائصـها ومشاكلها وتعريف الإسكان العشوائى ودراسة تأثيرها على النواحى العمرانية والبيئية والصحية. - - اسباب نشاة هذة التجمعات .

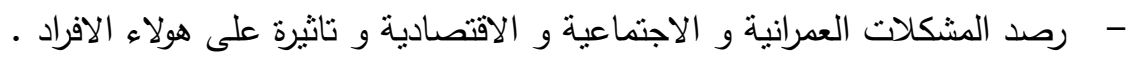

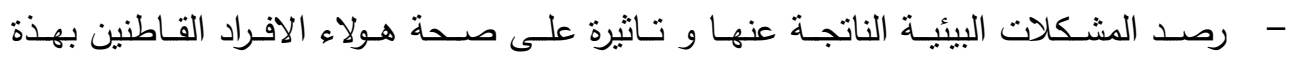

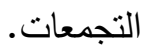
- - وضع و حلول و توصيات لمتل هذة التجمعات مع وضع استراتيجيات تعامل مع هذة المناطق

\section{المقة دمة}

تعتبرمشكلة العشوائيات والآثار المترتبة عليها من أهم الشكلات التى تقوم الدولة بمعالجتها وإيجاد حلول

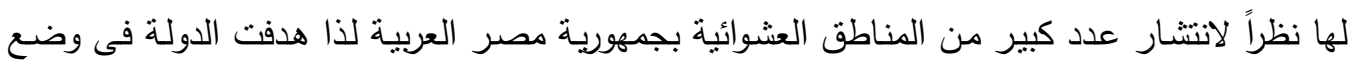
سياسة لمعالجة هذه المشكلة التى انتشرت بشكل كبير وملحوظ فى جمهورية مصر العربية وتقوم حالياً 
الدولـة برصد وتحديد عدد وأماكن المناطق العشوائية بجمهوريـة مصر العربيـة نظراً لللآثار السلبية الناتجة من هذه المناطق العشوائية سواء كانت آثار عمرانية أو اجتماعية أو اقتصادية أو بيئية .

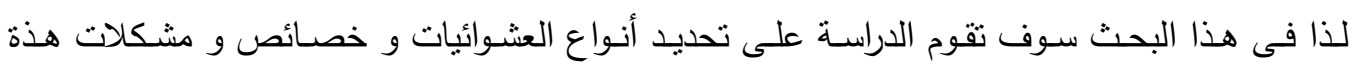

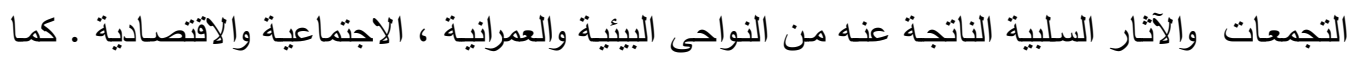
يستعرض اسباب نشاة هذة التجمعات على اطراف المدن.

\section{مجال البحث : مجث:}

يشمل مجال البحث دراسة المناطق العشوائية و تحديد مفهوم المناطق العشوائية من عدة مناظير ، كما

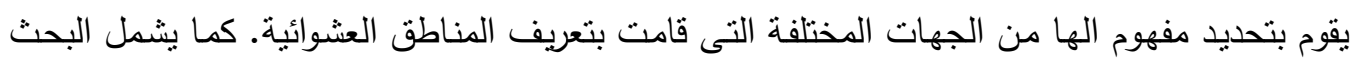
تحديد الانماط المختلفة لهذة المناطق و خصائص التجمعات العشوائية ، واسباب نثـاتها و المشاكل

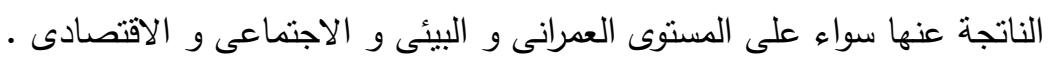

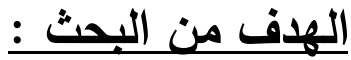

1-دراسة الانماط المختلفة للمناطق العشوائية مع تحليل لكل نمط من هذة الانماط و اماكن تواجدة.

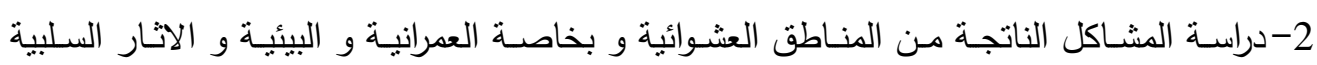
الناتجة عنها .

3-دراسة خصائص تلك التجمعات من النواحى العمرانية و الاجتماعية و الاقتصادية .

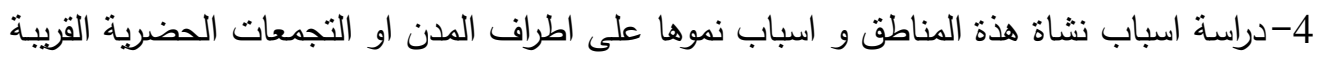
من مكان نشاتها. 5-دراسة الاثار البيئية التى نتجت من هذة المناطق العشوائية .

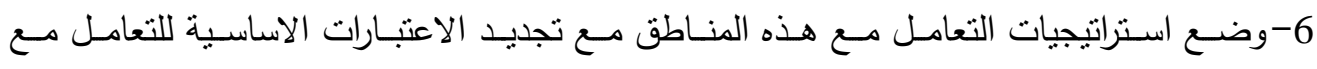
العشوائيات

ظهرت عدة مفاهيم عرفت المناطقة العشوائية و لكن قبل التعرض لمفهوم العشوائيات و يجب أولا مناقثة

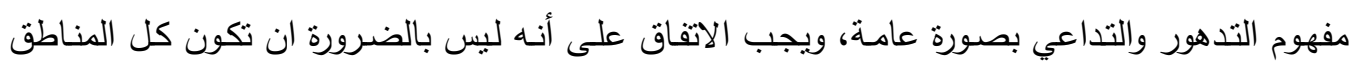

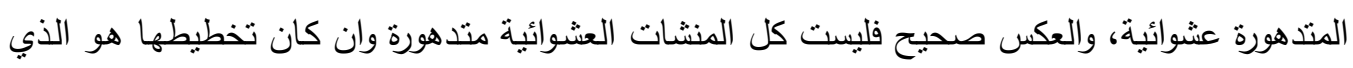

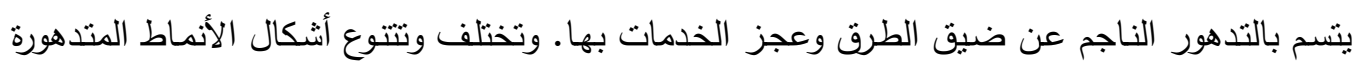

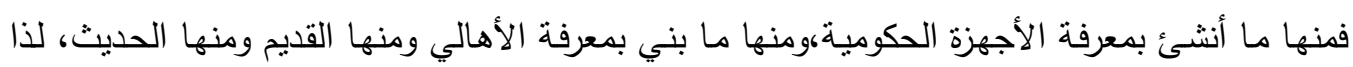

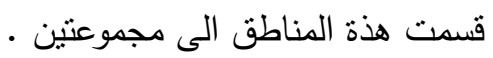


المجموعة الأولي: المناطق التي أنشئت بمعرفة الأجهزة الحكومية، أو بمعرفة الأهالي بعد الحصول علي التراخيص اللازمة. المجموعة الثانبة: المناطق التي بنيت و نمت بمعرفة الأهالي دون صفة رسمية وبها تجاوزات. 1 - المجموعة الأولىى: المناطق التي أنشئت بمعرفة الأجهزة الحكومية أو المباني المرخصة و يندرج تحت هذه المجموعة: 1- الأنوية والأحباء القديمة 2- المساكن الثعبية 3- مساكن الإيواء المؤقت

\section{1-الأنوية و الأحياء القديمة}

تعد النواة القديمة أحد أنماط السكن المندهور داخل العمران الحضري كما تعد النواة القديمة أحد الملامح الأساسية للمدينة المصرية وتتميز النويات القديمة بنسيج تخطيطي بطلق عليه الكتل العمرانية التراكمية

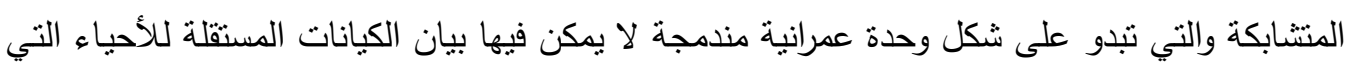

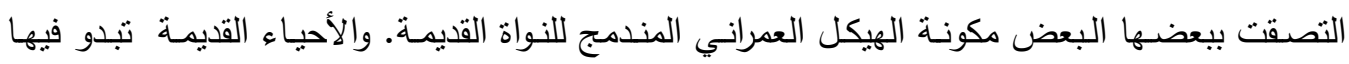

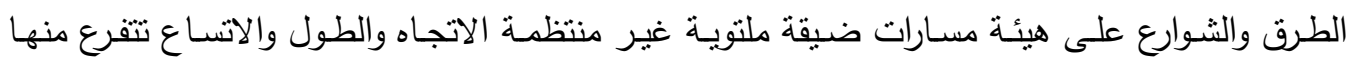

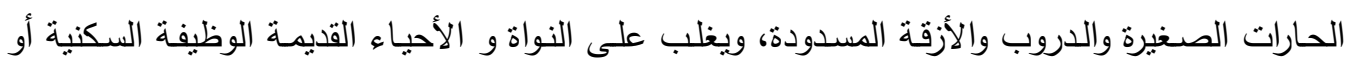

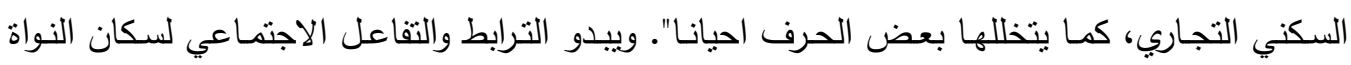
القديمة في إطار مجتمع الحارة الذي يتم التفاعل فيه في إطار الجيرة والسوق والمقاهي.

\section{2-المساكن الشعبية}

توجد المناطق المتدهورة في بعض الأحيان - تحت ظل التواجد الحكومي وبتصريح منه ووفق خطة عمرانية مدروسة وموافق عليها من قبل الهيئات والمؤسسات الحكومية وبخاصة الدحافظات الدات والإدارات المحلية، وتعد المساكن الثُعبية خير دليل على ذللى، فقامت الدولة منذ منتصف الخمسينيات بيناء

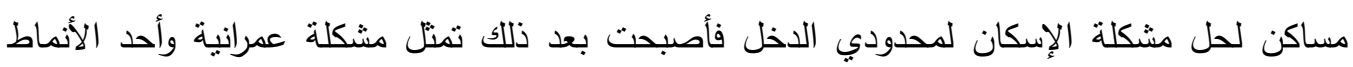
للتندور العمراني في خريطة مصر العمرانية. وقد تدهورت المساكن الشعبية لعدة أسباب منها رفع يد الدولة عنها بمجرد نسليمها للسكان وعدم قدرتها

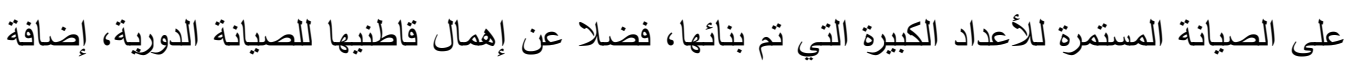

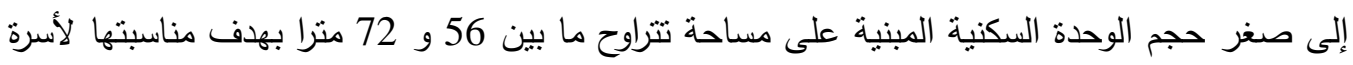

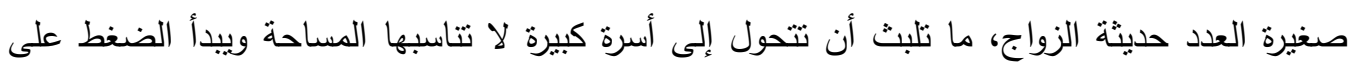


المرافق وتبدأ التعديات على الفراغات المجاورة بإقامة غرف جديدة، أو إضافة شرفات أخرى داخل
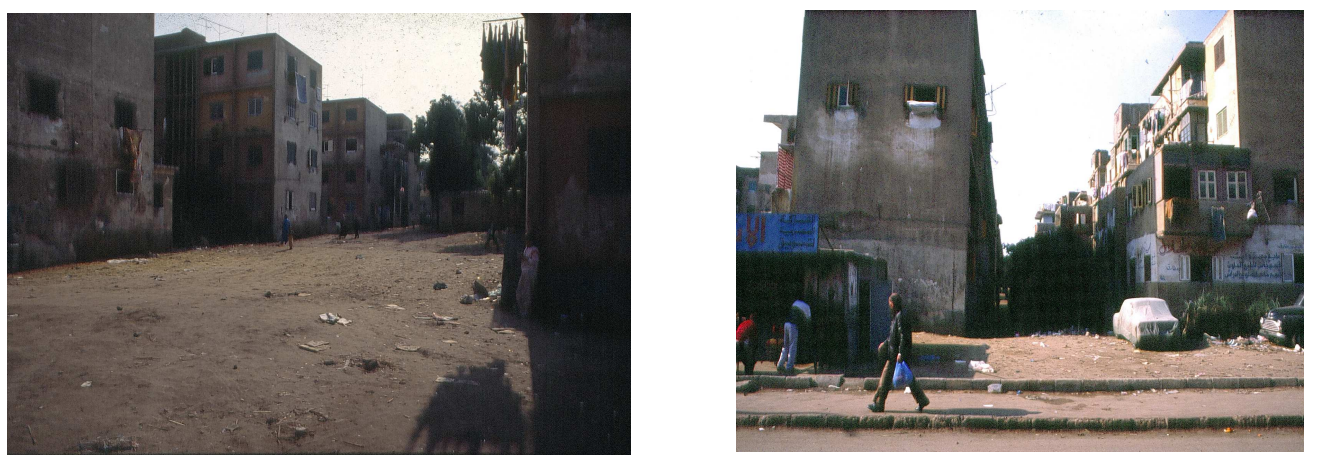

صورة توضح :الإسكان الثعبي في

منطقة عين الصيرة

\section{3- مساكن الإيواءع}

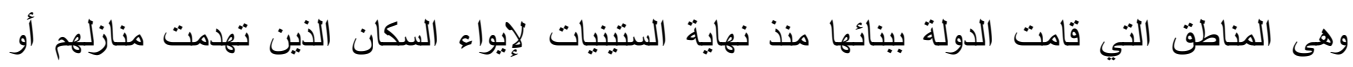

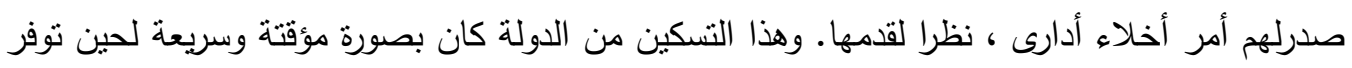

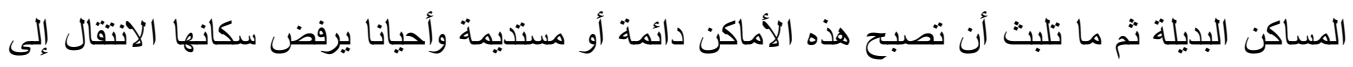

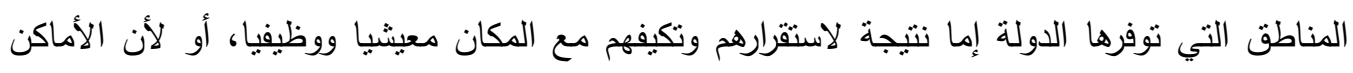
التي توفرها الدولة بعيدة ومكلفة من الناحية الإيجارية والمعيشية.

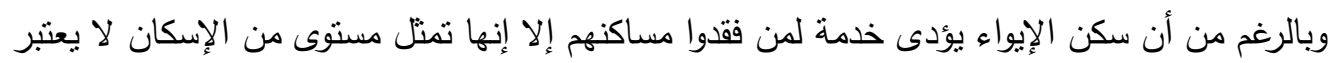
أدميا فلا يوجد نطابق في المواصفات الفنية للوحدات السكنية.

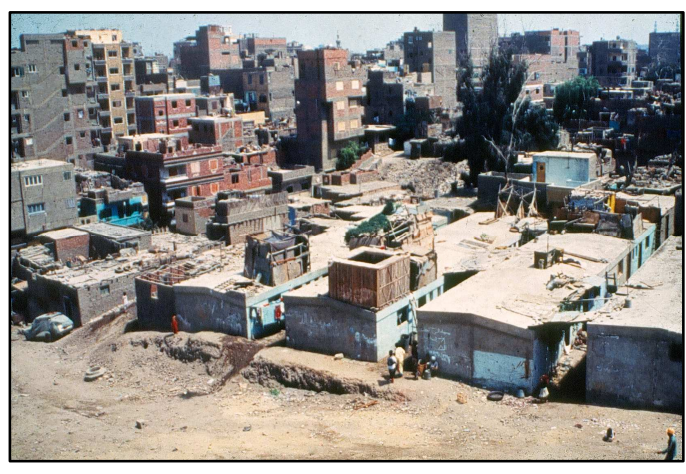

صورة توضح :إيواء زينهم

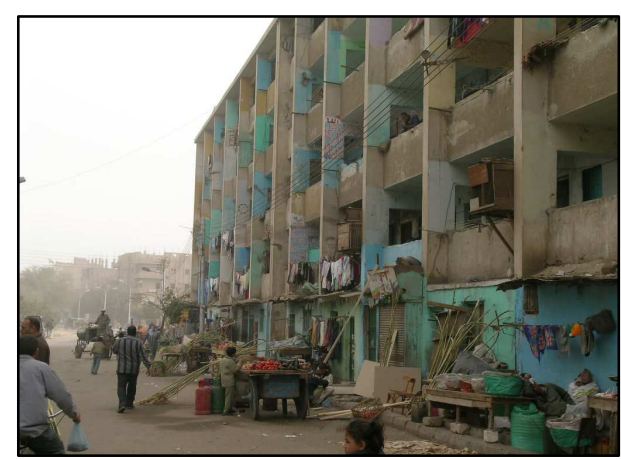

صورة توضح :إيواء السلخانة_المنيا 


\section{2- المجموعة الثانبة:}

المناطق التي نمت بمعرفة الأهالي/ المناطق غير الرسمية

و يندرج تحت هذه المجموعة:

1- الجيوب الريفية وسط التجمعات الحضرية

2- مناطق الزحف على الأراضي الزراعية

3- مناطق البناء علي أراضى ملك الدولة / وضع الارضي الزراعه اليد

\section{1-الجيوب الريفية/العشوائية وسط التجمعات الحضرية}

يشكل مصطلح "الجيوب" نمطان من أنماط التدهور ـ النمط الأول هو الجيوب التي تتخلل أحباء مخططة

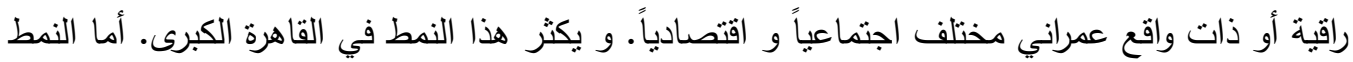

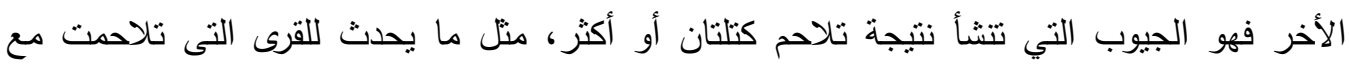

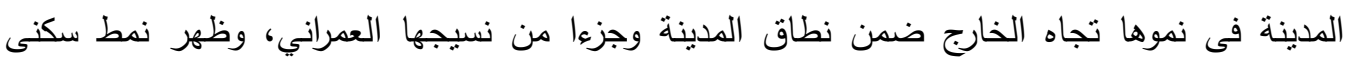

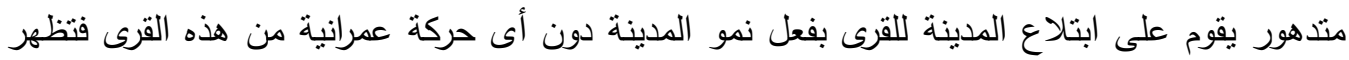

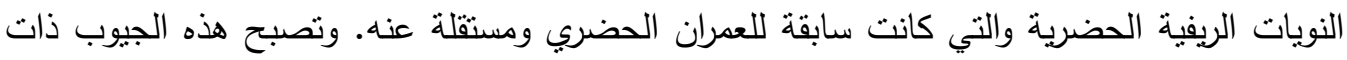

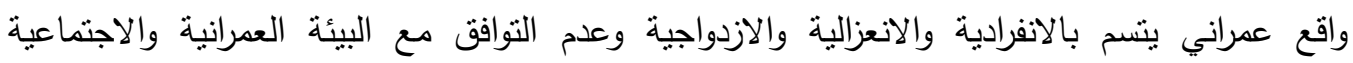

والاقتصادية المحيطة بها. كما ان نتأرجح حالة المباني ما بين المتوسطة والرديئة معظم الوحدات السكنية داخل تلأك الجيوب

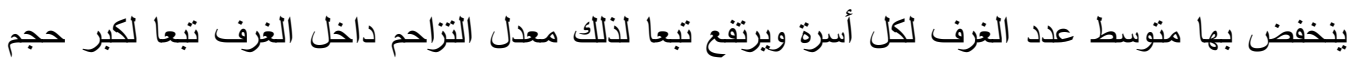
الأسرة والذي يتراوح ما بين 5,4 افراد فى المتوسط. بالإضافة إلي أن قطاعا كبيرا من السكان يعيشون

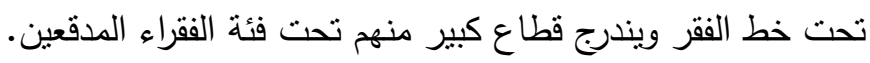

\section{2- مناطق الزحف على الأراضي الزراعية:}

استطاع نمو المدن مع نمو القرى فى آن واحد وفى اتجاه بعضهـا البعض أن يخلق نمطا من أنماط

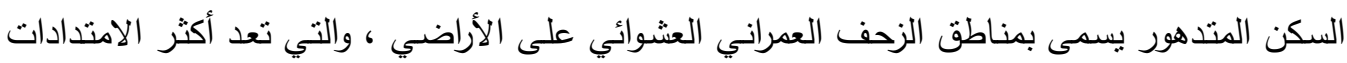

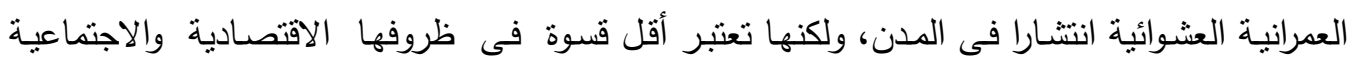
والسكنية فى حين تكون أكثر الأنماط خطورة على عمليات التخطيط وذلك نظرا لامتدادها المساحي

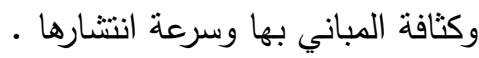
يتم البناء من قبل السكان بعمل سور من الطوب الأحمر والأسمنت لنأكيد الملكية وتبدو المنطقة عبارة

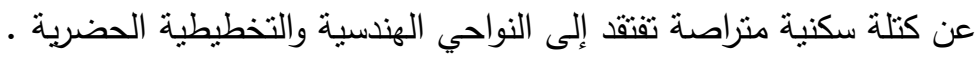




\section{3-مناطق البناء علي أراضى ملك الدولة / وضع اليد}

ينتشر هذا النمط في العديد من المناطق التي تمتلكها الدولة حيث تشتقر مجموعة من الأفراد في منطقة ما ويبدأ البناء متخذاً أثنكالاً متعددة، تبدأ بمباني من دور واحد ثم يضيف السكان أدوارا أخري بعد الاطمئنان أن الاستقرار المؤقت محتمل، وتتطور تللك المجتمعات وبطمع السكان في الحصول علي مميزات إضافية من بنية أساسية في حالة المجتمعات الهامشية التي تتشأ علي حدود الكتلة العمرانية كبدايات منشية ناصر • وحق في الحيازة ان أمكن. النوع الأخر هي المجتمعات التي تتخلل الكتلة القائمة كما هو الحال منطقة منشية ناصر • لذا سوف نقوم بتعريف المناطق العثوائية و تحديد انماطها المختلفة

\section{تعريف بالمنـاطق العشوائية}

توجد مداخل كثيرة وضحت تعريف للمناطق العشوائية كما ان لمناطق العشوائية كثير من الانماط منها اسكان القبور و اسكان العشش و إسـكان المخـابئ و اسكان القوارب ـ لذا قامت عدة جهات عرفت المناطق العشوائية ـ كما ظهرت عدة مداخل عرفت المنـاطق العشوائية منها مـا هو مرتبط بالمدخل العمرانى او الاقتصادى و الاجتماعى او القانونى •

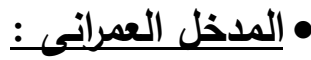

- تجمع عمرانى بلا خطة ، وينصرف ذلك التعريف الى عدة تطبيقات منها غياب خطة نموذجية شاملة Master Plan فى مواجهة الخروج عليها .

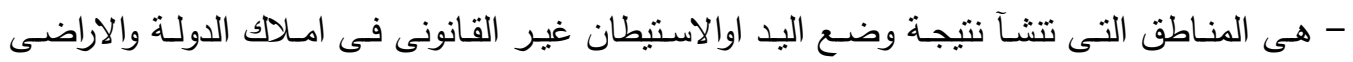
الفضاء ، وبالتالى تكون غير مخططة عمرانياً منذ نشائها والتى تعانى من نقص اساسى فى الخدمات والمرافق الرئيسية ، واهمها الصرف الصحى والمياه النقية .

\section{• المدخل الاقتصادى الاجتماعى:}

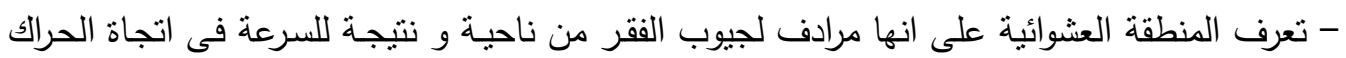

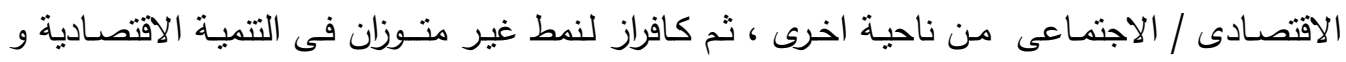
الاجتماعية من ناحية ثالثة .

- " العشوائية " هى منطقة يقبل القانطون بها معيشة إجتماعية متدنية ، بل ويقبلون على النزوح إليها ، بسبب محدودية إمكاناتهم الإقتصادية للحصول على مسكن في المناطق المخططة والأرقى والأغلى ،

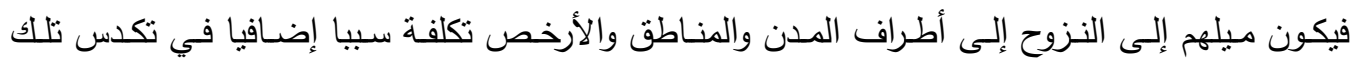


المناطق وتدهور ظروفها المعيشية ، فتتحول إلى حد جيوب الفقر Poverty Pockets بالمناطق

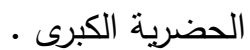

جدول يوضح : عدد سكان المناطق العشوائية والنسبة المئوية إلى عدد سكان الحضر فى بعض محافظات الجمهورية عام2005 ل (السكان بالألف)

\begin{tabular}{|c|c|c|c|c|c|}
\hline \multirow{2}{*}{ سكان العشائية إلى } & \multicolumn{2}{|c|}{ 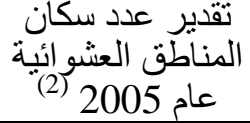 } & \multirow{2}{*}{ تقدير عدد } & \multirow{2}{*}{ العشاطو ائية } & \multirow[t]{2}{*}{ المحافظة } \\
\hline & $\%$ & العدد & & & \\
\hline 29.1 & 36.28 & 2260 & 7765 & 76 & القاهرة \\
\hline 7.7 & 4.72 & 294 & 3821 & 44 & الإسكندرية \\
\hline 1.8 & J16 & 9.7 & 538 & 7 & بور سعيد \\
\hline 2.3 & J18 & 11.2 & 488 & 8 & السويس \\
\hline 56.1 & 2.83 & 176 & 314 & 88 & دمياط \\
\hline 28.1 & 6.25 & 389 & 1386 & 121 & الدقهلية \\
\hline 33.4 & 6.29 & 392 & 1173 & 83 & الثرقية \\
\hline 41.1 & 10.29 & 641 & 1559 & 62 & القليو بية \\
\hline 27.9 & 2.76 & 172 & 615 & 50 & كفر الثنيخ \\
\hline 12.2 & 2.39 & 149 & 1224 & 46 & الغربية \\
\hline 24.5 & 2.52 & 157 & 641 & 53 & المنوفية \\
\hline 30ر- & 5.35 & 333 & 1109 & 80 & البحيرة \\
\hline 30.2 & 2.12 & 132 & 436 & 13 & الإسماعيلية \\
\hline 24.2 & 13.15 & 819 & 3385 & 36 & الجيزة \\
\hline 16.3 & 1.40 & 87 & 531 & 42 & بنى سويف \\
\hline 6.5 & j58 & 36 & 549 & 28 & الفيوم \\
\hline- & - & - & 779 & - & المنيا \\
\hline 7.7 & 1.15 & 72 & 937 & 22 & اسيوط \\
\hline $1 \mathrm{~J}$ & J13 & 8.4 & 844 & 26 & سو هاج \\
\hline- & - & - & 622 & - & قنا \\
\hline 1.8 & J06 & 3.5 & 197 & 15 & الاقصر \\
\hline 54 & J03 & $2 ر-$ & 491 & 2 & أسوان \\
\hline 7.9 & ر18 & 11 & 139 & 1 & البحر الاحمر \\
\hline- & - & - & 83 & - & اللو ادى الجديد \\
\hline 35.6 & (90 & 56 & 157 & 5 & مطروح \\
\hline 9.5 & J28 & 17.5 & 184 & 1 & شمال سيناء \\
\hline- & - & - & 31 & - & جنوب سيناء \\
\hline 20.8 & 100ر- & 6228 & 29998 & 909 & الجملة \\
\hline
\end{tabular}

(1) الجهاز المركزي للتعبئة العامة والإحصاء، مصر فى أرقام 2004، إبريل 2005. (2) الثقدير بمعرفة الباحث بالطريقة الحسابية. 


\section{: المدخل القانونى و الادارى}

- هى منطقة العشـوائية لايجوز البناء عليها لاسباب قانونيـة. فالمعيار لدى هذا المدخل هو الاحتكام الى القوانين المنظمـة للنمو العمرانى و بنـاء المساكن و الذى يرتكز على القانون رقم 3 لسنة 1982

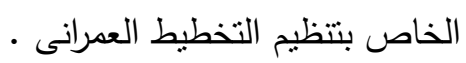

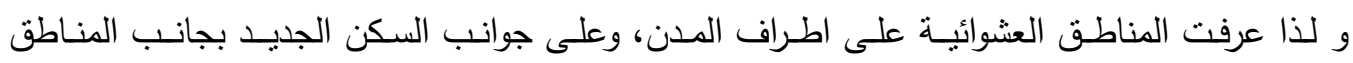

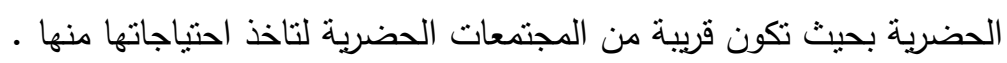

\section{تعريف مجلس الثوري}

تقربر مجلس الثورى- عام 1996 المناطق العشوائية هى عبارة عن تجمعات سكانية نشأت فى غياب التخطبط العام و خروجا عن القانون

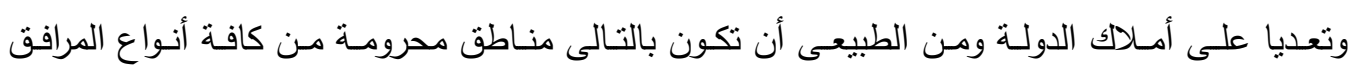
والخدمات الاساسية من مياه وكهرباء بل ليس بها نقطة شرطة أو وحدة صحية أو مدرسة أونس أو مواصلات

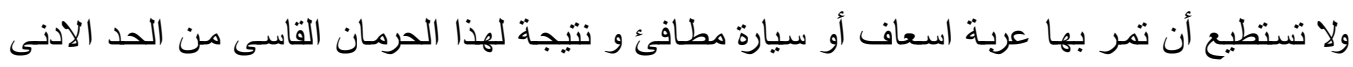

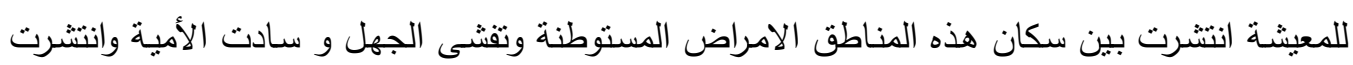

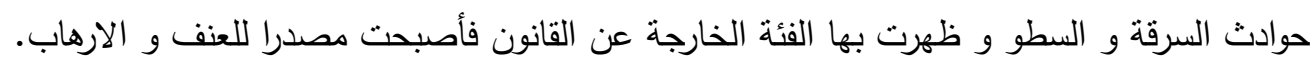

\section{تعريف الجهاز المركزي للتعبئة العامة والإحصاء}

الهناطق التي أقيمت بالجهود الذاتية سواء علي أرضهم أو علي أرض الدولة بدون تراخيص رسمية ولألذا

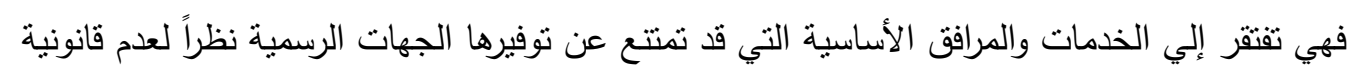
هذه الوحدات .

\section{تعريف الامح المتحدة}

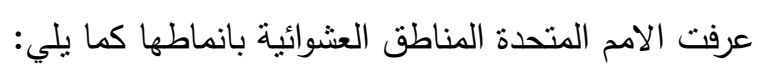

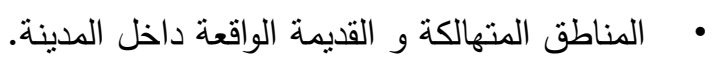

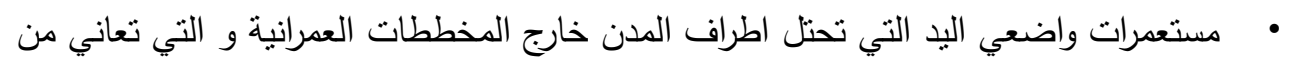

$$
\text { عدم الاعتراف بشرعيتها. }
$$

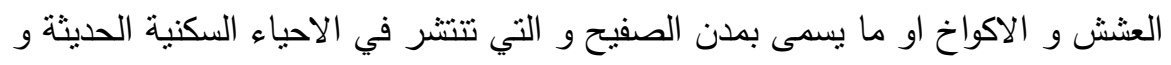
القديمة على حد سواءفي قلب المدن او على هوامشها.

جدول يوضح : تقدير حجم سكان العشوائيات بمحافظات الجمهورية خلامل الفترة 2022/2012 


\begin{tabular}{|c|c|c|c|}
\hline \multicolumn{3}{|c|}{ تقدير عدد السكان (بالألف) } & \multirow{2}{*}{ المحافظة } \\
\hline 2022 & 2017 & 2012 & \\
\hline 2906 & 2699 & 2506 & القاهرة \\
\hline 370 & 346 & 324 & الإسكندرية \\
\hline 11.5 & 10.9 & 10.4 & بور سعيد \\
\hline 15 & 13.8 & 12.6 & السويس \\
\hline 258 & 233 & 208 & دمياط \\
\hline 530 & 484 & 442 & الدقهلية \\
\hline 555 & 504 & 455 & الشرقية \\
\hline 854 & 785 & 721 & القليوبية \\
\hline 240 & 219 & 198 & كفر الثيخ \\
\hline 191 & 178 & 166 & الغربية \\
\hline 206 & 191 & 177 & المنوفية \\
\hline 467 & 425 & 385 & البحيرة \\
\hline 184 & 168 & 152 & الإسماعيلية \\
\hline 1330 & 1158 & 1004 & الجيزة \\
\hline 122 & 111 & 101 & بنى سويف \\
\hline 53 & 47 & 42 & الفيوم \\
\hline 99 & 91 & 83 & أسيوط \\
\hline 12.5 & 11.1 & 9.9 & سو هاج \\
\hline 4.7 & 4.3 & 3.9 & الأقصر \\
\hline 2.4 & 2.3 & 2.1 & أسوان \\
\hline 15.1 & 13.8 & 12.5 & البحر الأحمر \\
\hline 90 & 79 & 69 & مطروح \\
\hline 25.5 & 22.9 & 20.5 & شمال سيناء \\
\hline 8542 & 7797 & 7105 & الجملة \\
\hline
\end{tabular}


إسكان القبور

سكان أحواش المدافن يقيمون في غرفة واحد بالدافن أو يقيمون في غرفنتن ولا يزيد عدد الغرف على

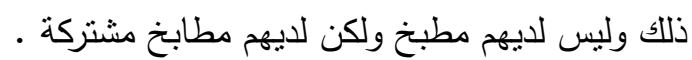

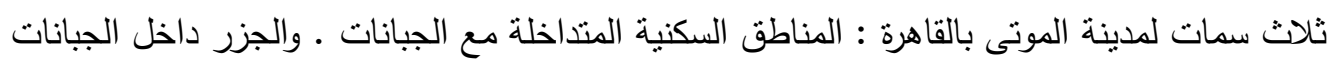
وسكان أحواش المقابر

\section{إسكان القوارب :}

سكان القوارب نمط آخر من الإسكان حيث تقيم أسر كاملة في قوارب صغيرة بالنيل نأكل وتترب وتطبخ

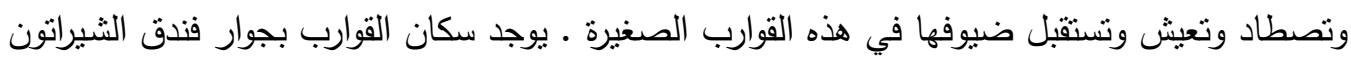

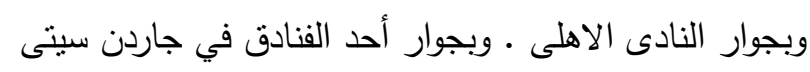

إسكان المخابئ :

في بعض المخابئ التى أقيمت للإحتماء بها وقت الغارات الجوية في الحدائق العامة ، تقيم بعض الأسر

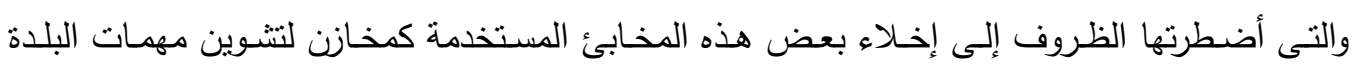

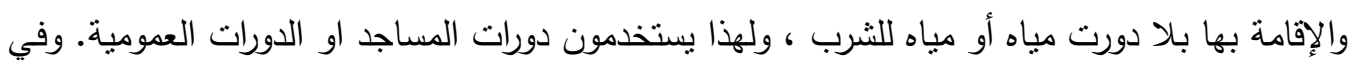

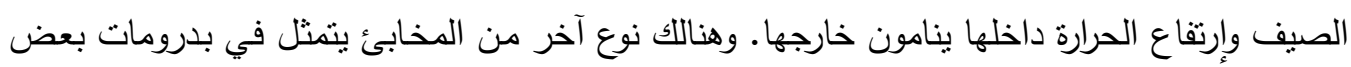

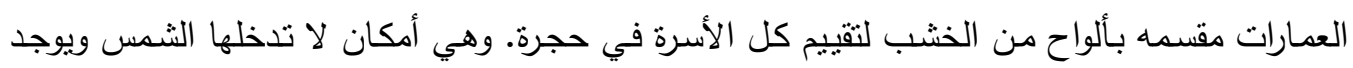
عدد منها بمدينة دمياط.

اسكان الاكاكين :

هو تسكين بعض الأسر في الدكاكين المقامة بالعمارات السكنية رغم أن الدكاكين بلا فتحات تهوية وليس

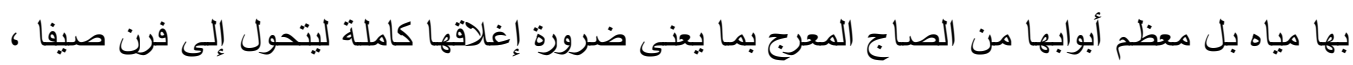

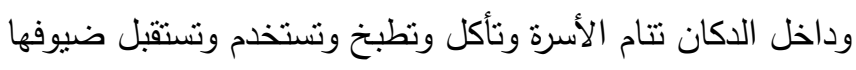

\section{اسكان قبوات السلالٍ :}

هو سكن من سانر خثبى به باب لإغلاق قبوة السلم فإن البعض لم يجد امامه سوى ذلك الحل ، خاصة

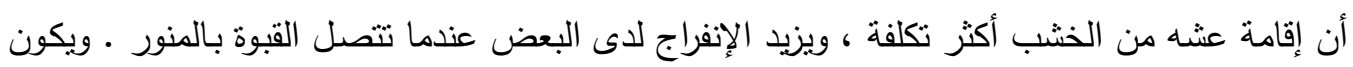

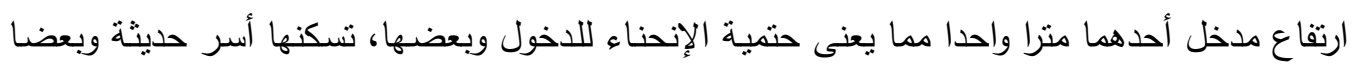

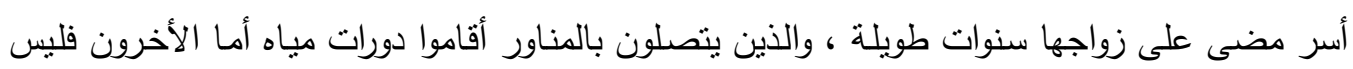
لديهم دروات مياه ـ كما ان منهم يسكنون قبوات السلم و بعض منهم يعملون بوابين في العمارات الجديدة 
العثش:

تعبر العشش ومدن الصفيح عن أسوأ حالات الظاهرة الحضرية وتشكل فى نفس الوقت تلاحما قويا مع التحضر وظهور الهجرة الريفية الحضرية بالتقاليد القروية مما يجعل من مناطق العشش ومدن الصفيح مرحلة انتقالية بين المجتمع القروي من جهة والمجتمع الحضري من جهة أخرى وهذا من الناحية السلوكية، أما على المستوى العمراني فتعد العشش أدنى المراتب السكنية.

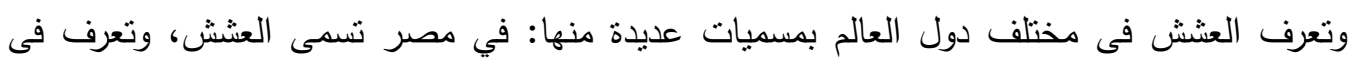
فرنسا بالأحياء القصديرية، وتعرف فى العراق باسم الصرائف وباسم شانتى تاون فى المدن الإنجليزية،

وباسم العشيش فى الكويت، والتخاثشيب فى لبنان. وتتوزع العشش في مصر على النحو النالي: - العشش على ضفاف نهر النيل. (عشش نرعة الإسماعيلية وتم إزالتها بمعرفة محافظة القاهرة). - العشش على طول محاور السكلك الحديدية. (عشش منطقة أبو رجيلة بعين شمس) - العشش فى المناطق الصناعية. - نطاقات العشش الواقعة في زمام الترع والمصارف. - العناع.

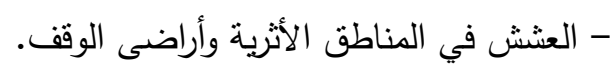

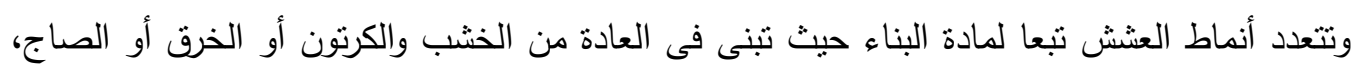

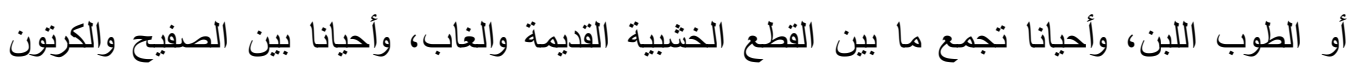
وأحيانا بين الصاج والخيش.

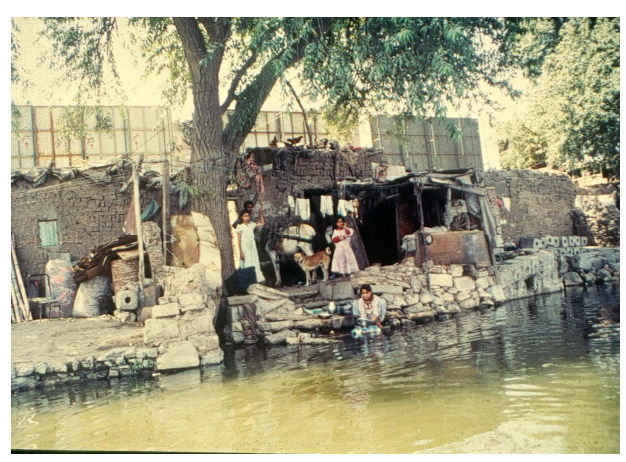

صورة توضح :عشش ترعة الإسماعيلية

اسبـاب نشـاه المناطق العثوائبـة.

-ترجع اسباب نشاة المناطق العشوائية الى حاجة هولاء الافراد لمساكن لهم و كذللك تتشا تلك المناطق

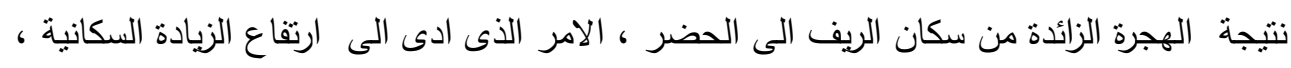

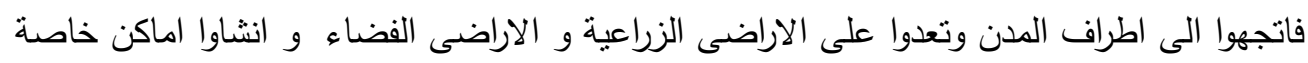
بهم ، ويمكن تفسير اسباب ذلك الى الى 
- ظهور التتمية الصناعية بالمدن الكبرى وعدم الرغبة فى العمل الزراعى بالمناطق الريفية - تحويل المناطق الحضاريه الى مناطق جذب بما تقدمة من فرص عمل. - عدم رغبة الوافدين من الريف فى التعامل مع الجهات الرسميه.

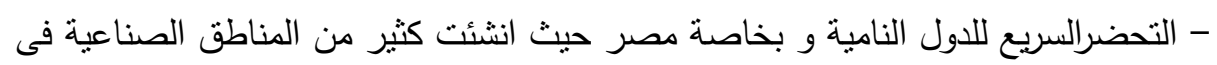
مصر و بخاصة المناطق القريبة من حلوان . - ادى نشاة المناطق العشوائية الى ارتفاع اسعارالوحدات السكنية داخل المناطق الحضية الحضرية لذا اتجة

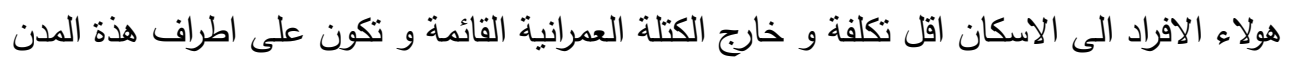

\section{مشاكل المنـاطق العثوائبــة}

\section{المشاكل العمرانية بالمناطق العثوائية :}

1- انعدام المسطحات الفضاء التى يمكن استغلالها كمتتفس للهواء للحد من اثر التلوث الناتج عن

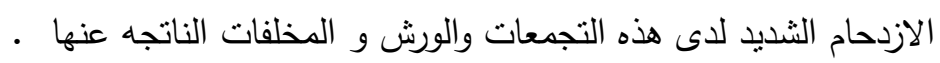

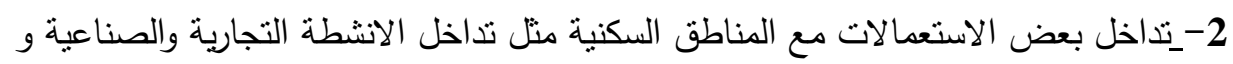

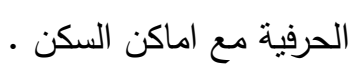

3- الكثافة السكانية العالية مع نقص العص فى الخدمات القائمة.

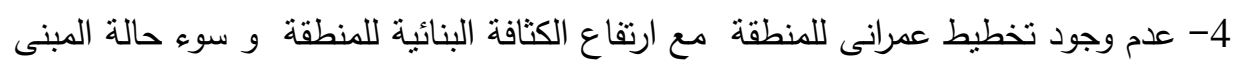

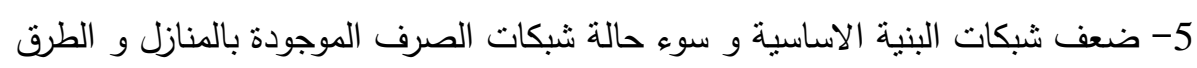
الرئيسية .

$$
\begin{aligned}
& \text { 6- ضعف شبكات الانارة بالطرق . } \\
& \text { 7- سوء حالة الطرق • }
\end{aligned}
$$

\section{المشاكل البيئية بالمناطق العثوائية :}

غياب الوعى الصحى نظرا لكثرة الامراض الناتجة عن وجودة انشطة حرفية مثل ورش، ومسابك

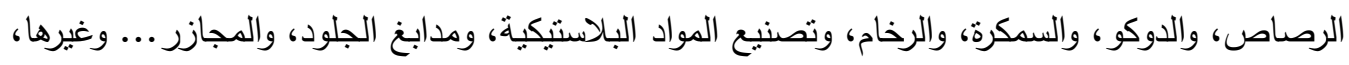

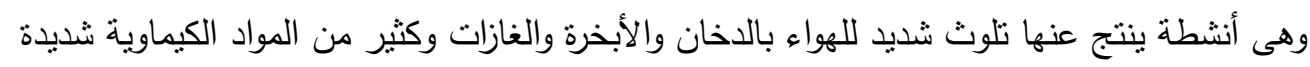

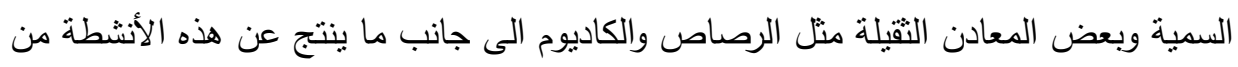
ضوضاء 1- ظهور مثير من الامراض الصدرية و التنفسية لدى الاطفال الناتجة من سوء

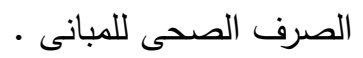


3-عدم وجود مناطق خضراء نساعد على تتقية الهواء .

4- المباني نفسها لا نراعى فيها الأصول الهندية من حيث الأمان والأتساع ومنافذ الهواء

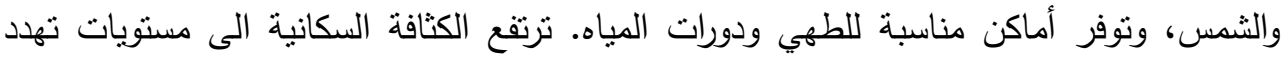
الصحة العامة والصحة النفسية والعقلية وتفقدها أهم عنصر من عناصر المسكن وهو الخصوصية. 3-فى هذة التجمعات السكنية لا تراعى فيه الثروط البيئية السليمة ويتكدس فيه السكان ولا تتوفر فيه المرافق من مياه شرب نقية وخدمات صرف صحي وطرق، وتتكدس فيه أكوام القمامة والتي يتم حرقها فى أحيان كثيرة، والمخلفات الصلبة، ويفتقر الى الخدمات من تعليم وصحة وملاعب، فانه يصبح مرتعا خصبا للأمراض ويمكن إيجاز أهمها فيما يلي:

أ- أمراض تتتج عن عدم توفير المياه النقية وخدمات الصرف الصحي وأهمها الإسهال والتيفويد والالتهاب الكبدي الوبائي وشلل الأطفال، وأمراض طفيلية معوية مثل التل

$$
\text { الإسكارس و }
$$

ب- أمراض تتتج عن تكس السكان ونقص التهوية مثل النزلات الثعبية والالتهاب الرئوي والدرن والحمى الروماتيزمية ومضاعفاتها فى القلب والكليتين والجهاز العصبي الى لى

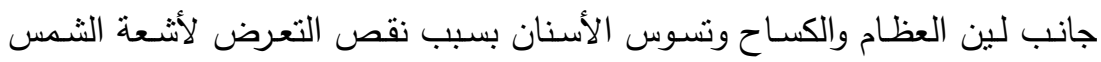

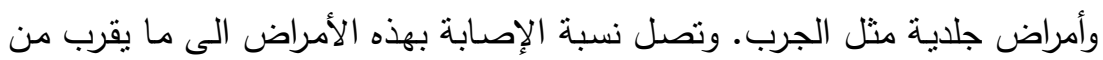
ضعف نسبتها بين من يسكنون فى مساكن صحية ونية
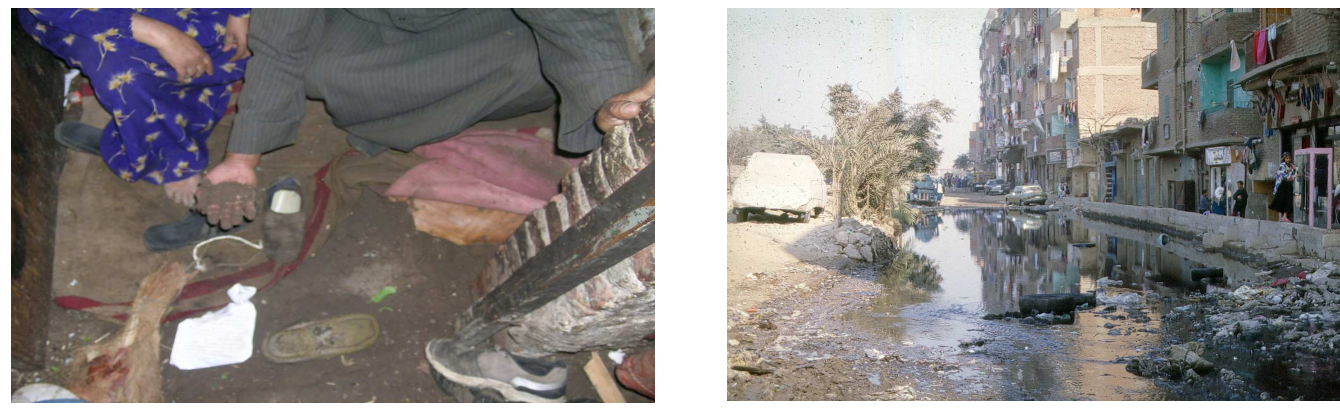

صورة توضح :المساكن تعاني من طفح المجاري صورة توضح :التلوث في المناطق العشوائية

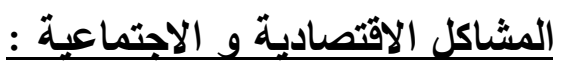

1 - ميادة نسبة التفكك الاسرى •

2- 2 - ارتفاع نسبة الامية بالمنطقة. 


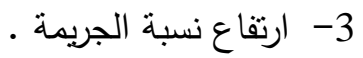

4-انخفاض المستوى الاقتصادى لسكان هذه المناطق لذلك اتجهوا الى انشاء العشش . 5- زيادة نسبة التسرب من التعليم •

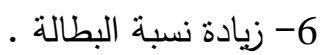

7- عدم الاهتمام بالاتجاة الى التعليم الجماعى.

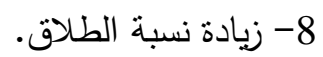

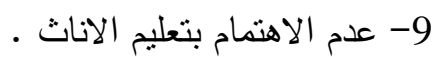

10- الاتجاة اى الاعمال الحرفية لزيادة كسب المال مع عدم الاهنمام بالاثار الصحية و البيئية

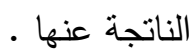

\section{النتائجج و التوصبات}

يجب اولا ان نتعامل مع المناطق العشوائية من خلال عدة استراتيجيات و مع تحديد الاعتبارات

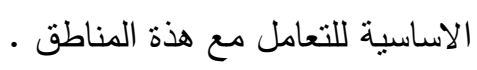

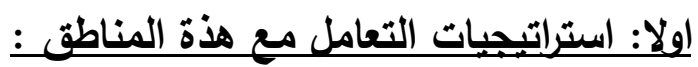
الاستراتعية الاولمى.

1 - دراسة لمعرفة رغبة هؤلاء الافراد لنطوير منطقتهم •

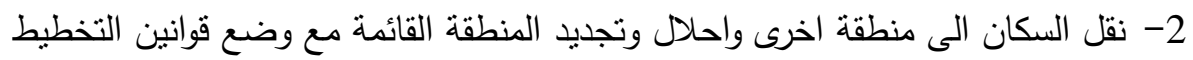

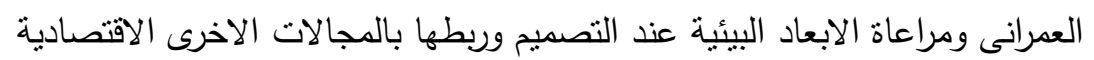
والاجتماعية والعمرانية .

3- وضع معايير تصميم التخطيط البيئى فى المنطقة مع مراعاه نوعية التربة والمناخ عند اختيار

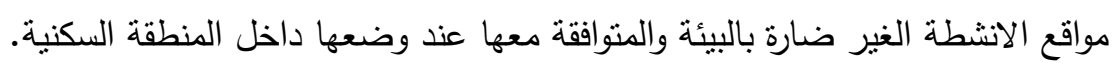
4- نقل الانشطة الضارة خارج الكتلة السكنية .

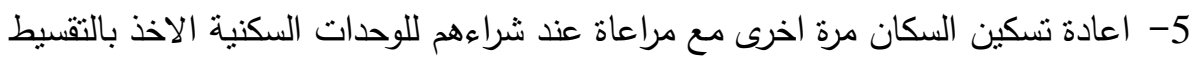

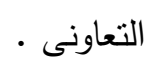

6- تحديد الجهات التى تمول المشروع •

الاستبراتيحية الثانية .

1- ازالة المبانى المتهالكة ووضع مبانى خدمات تحل محلها . 2- تحديد شبكات الطرق الرئيسية للمنطقة وتحديد الحدود الادارية للمنطقة . 


\section{الاستراتيحية الثالثة .}

1- تحديد مشكلات المنطقة وتحديد اولويات السكان وتحديد المحددات والامكانات المتاحة.

2- نشر برامج التوعية للسكان والتدريب والتأهيل .

3- دفع كفاءة خدمات المرافق .

4- التركيز على تتمية المسئولية الاجتماعية والعمل الجماعى بين السكان فى حل مشكلات

المنطقة .

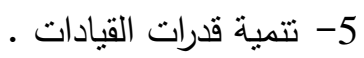

6- تحديد جهات التمويل التى تساعد على تمويل المشروع •

\section{الاعتبارات الأساسية للتعامل مع العثوائيات}

هناك مجموعة من الاعتبارات التي ينبغي مراعاتها لنجاح هذا المشروع والوصول به إلي حيز النطبيق: ضرورة وجود دعم سياسي (وبالتأكيد فهناك إرادة سياسية على مستوى كل القيادات للنتخل

$$
\text { فى حل مشاكل العشوائيات). }
$$

ضرورة بناء قاعدة بيانات أساسية عن كل العشوائيات من خلال منهجية واضحة لتنظيم

المعلومات. مع إمكانية ربط هذه البيانات بالمناطق المحيطة (city wide strategy).

تحقيق اللامركزية في التعامل مع العشوائيات.

ضرورة توافق كل الجهات المعنية والتتسيق بينها ومشاركتها فى وضع هذه الإستراتيجية

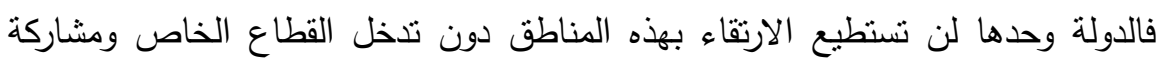
الأهالي.

التركيز على مبدأ المشاركة والثراكة في العملية التتموية وتكوين فرص استثمارية حقيقية. ضرورة رفع كفاءة وإمكانيات المحليات التي يقع علي عاتقها تتفيذ ومتابعة عمليات

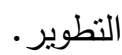

تحقيق إمكانية استرداد التكلفة. اختيار البرنامج التحسين البيئى و العمرانى و الارتقاء المناسب و الملائم لكل منطقة طبقاً لظروفها.

\section{فهرس المراجع}

- أحمد خالد علام ، تجديد الأحياء ، مكتبة الأنجلو 1993 ، طبعة أولى . 
- إكرام عبد العزيز ، رسالة ماجستير تخطيط تجمعات الصناعات الحرفية الجديدة فى مصر ،

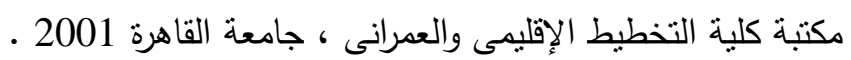
- أميرة كمال محمد ، رسـالة ماجستير دور المشـاركة الثـبية فى تطوير المناطق العشوائية ، دراسـة ميدانيـة على منطقة زينهم ، مكتبـة معهد الدراسـات والبحـوث البيئيـة المتبادلـة لعمارة وعمران القرى السياحية دراسة تحليلية للتقييم البيئى للقرى السياحية لمنطقة شرم الثيخ ، مكتبة كلية الهندسة ، جامعة القاهرة 1998 . 1998 - - تقرير العشوائيات ، الهيئة العامة للتخطيط العمرانى ، 2007 ، - - حسن أبو بكر وآخرون ، مـؤتمر العربى الإقليمسى لتأمين الحيازة / الإدارة الحضسارية الجيدة

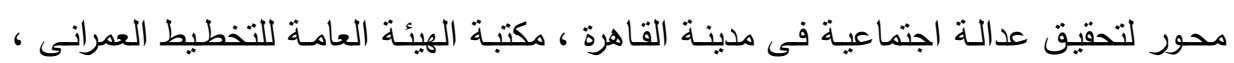
أبريل 2001 . 2001

- غـادة محمـد ريحـان ، رسـالة ماجستير عمليـة الارتقاء بالمنـاطق العشـوائية فى فاعليـة تتفيذ المخططسات مـع ذكر خـاص لمنطقة المنيرة الغربيـة محافظـة القاهرة ، مكتبـة كليـة الهندسـة ، جامعة القاهرة ، 2000 . - فراج عطا سـالم ، رسالة دكتوراه التتمية البيئية والاجتماعية فى المجتمعات العشوائية بالقاهرة والجيزة ، مكتبة معهد الدراسات والبحوث البيئية ، جامعة عين شمس ، 1998 ـ - - نادر لويس نقولا ، رسالة ماجستير مناطق الإسكان العشوائى بالقاهرة دراسة حالة منطقة بولاق ، الدكرور من الوجهة المعمارية والاجتماعية ، مكتبة معهد الدراسات والبحوث البيئية ، 1997. 